\title{
Abordagens geográficas e o uso das Tecnologias de Informação e Comunicação na atual práxis docente em geografia humana: Uma revisão narrativa
}

Geographical approaches and the use of Information and Communication Technologies in current teaching praxis in human geography: A narrative review

Los enfoques geográficos y el uso de las Tecnologías de la Información y la Comunicación en la práctica actual de la enseñanza de la geografía humana: Una revisión narrativa

Recebido: 30/06/2021 | Revisado: 06/07/2021 | Aceito: 14/07/2021 | Publicado: 24/07/2021

Leandro Alcasar Rodrigues

ORCID: https://orcid.org/0000-0003-3523-0570 Secretaria da Educação da Prefeitura Municipal de Jardinópolis, Brasil e-mail.leandroalcasar@yahoo.com.br

Márcia Isabel Gentil Diniz

ORCID: https://orcid.org/0000-0003-1980-4597 Universidade Federal Fluminense, Brasil e-mail: marciagentil@uol.com.br

\begin{abstract}
Resumo
$\mathrm{Na}$ atualidade, o ensino da geografia humana aliada ao uso das tecnologias de informação e comunicação (TIC's) vem sendo largamente utilizado em diversos contextos educacionais. Tal atuação tem permitido que o processo ensinoaprendizagem na geografia tenha um maior alcance com eficácia em termos de aprofundamentos teóricos nessa área de conhecimento. O uso de (TIC's), parece ser acertado e bem direcionado no que tange especificamente a formação de futuros professores de Geografia, sobretudo, na Geografia Humana onde está ocorrendo um processo de potencialização dos debates acerca do papel do ensino da Geografia na Educação. Considera-se aqui especialmente o ensino da Geografia Humana que engloba diversas disciplinas tais como Política, Comercio, Legislação, Meio Ambiente entre outras áreas do conhecimento e vislumbra-se daí uma nova tendência, visto que a linguagem geográfica hoje necessita ser ampliada, acrescentando reflexões profundas sobre a definição não somente dos significados, mas também de representações que podem ser atribuídas a termos diversificados tais como: "meioambiente, identidade cultural, degradação ambiental, " entre outros. Indaga-se então: a utilização das ferramentas proporcionadas pelo advento das TIC's contribuem para avanço do conhecimento no processo de ensino aprendizagem em geografia humana onde o professor possa fomentar a autonomia e o pensamento crítico do seu aluno. O presente trabalho metodologicamente é de natureza bibliográfica e narrativa produzindo discussões voltada para uma perspectiva de construção de conhecimentos no qual a geografia deve sempre se manter como ciência, onde se desenrola acontecimentos sendo fundamental para todos os processos de construção social e estruturante de uma sociedade complexa.
\end{abstract}

Palavras-chave: TICs; Geografia; Geografia humana; Educação; Ensino-aprendizagem.

\begin{abstract}
Nowadays, the teaching of human geography allied to the use of information and communication technologies (TICs) has been widely used in several educational contexts. Such action has allowed the teaching-learning process in geography to have a greater reach with effectiveness in terms of theoretical deepening in this area of knowledge. The use of TICs seems to be right and well directed towards the training of future Geography teachers, especially in Human Geography, where a process of strengthening the debates about the role of Geography teaching in Education is taking place. Here we consider especially the teaching of Human Geography, which encompasses several disciplines such as Politics, Commerce, Legislation, Environment, among other areas of knowledge, and we glimpse a new trend, since the geographic language today needs to be expanded, adding deep reflections on the definition not only of meanings, but also of representations that can be attributed to diverse terms such as "environment, cultural identity, environmental degradation," among others. The question then is: does the use of the tools provided by the advent of TICs contribute to the advancement of knowledge in the teaching-learning process in human geography where the teacher can foster the autonomy and critical thinking of his student. The present work methodologically is of bibliographical and narrative nature producing discussions focused on a perspective of knowledge construction in which geography should always remain as a science, where events unfold, being fundamental to all processes of social construction and structuring of a complex society.
\end{abstract}

Keywords: TICs; Geography; Human geography; Education; Teaching-learning. 


\begin{abstract}
Resumen
Hoy en día, la enseñanza de la geografía humana aliada al uso de las tecnologías de la información y la comunicación (TIC) ha sido ampliamente utilizada en varios contextos educativos. Tal desempeño ha permitido que el proceso de enseñanza-aprendizaje en geografía tenga un mayor alcance con efectividad en cuanto a la profundización teórica en esta área del conocimiento. El uso de las (TIC's), parece ser acertado y bien dirigido en lo que se refiere específicamente a la formación de futuros profesores de Geografía, sobre todo, en la Geografía Humana donde se está produciendo un proceso de potenciación de los debates sobre el papel de la enseñanza de la Geografía en la Educación. Se considera aquí especialmente la enseñanza de la Geografía Humana que incluye varias disciplinas como la Política, el Comercio, la Legislación, el Medio Ambiente entre otras áreas del conocimiento y se vislumbra desde allí una nueva tendencia, ya que el lenguaje geográfico hoy en día necesita ser ampliado, añadiendo reflexiones profundas sobre la definición no sólo de significados, sino también de representaciones que se pueden atribuir a diversos términos como "medio ambiente, identidad cultural, degradación ambiental", entre otros. Se pregunta entonces: el uso de las herramientas proporcionadas por el advenimiento de las TIC's contribuyen al avance del conocimiento en el proceso de enseñanza aprendizaje en geografía humana donde el profesor puede fomentar la autonomía y el pensamiento crítico de su alumno. El presente trabajo metodológicamente es de carácter bibliográfico y narrativo produciendo discusiones centradas en una perspectiva de construcción del conocimiento en la que la geografía debe permanecer siempre como una ciencia, donde los acontecimientos se desenvuelven siendo fundamentales para todos los procesos de construcción social y estructuración de una sociedad compleja.

Palabras clave: TICs; Geografía; Geografía humana; Educación; Enseñanza-aprendizaje.
\end{abstract}

\title{
1. Introdução
}

A geografia humana perpassa a geografia física e com ela constrói através do uso das tecnologias de informação um aprendizado horizontal que ao invés de fragmentar o ensino da geografia como um todo, a fortalece como instrumento de cidadania e resgate dos Direitos Humanos e fundamentalmente do aspecto este significativo e pertinente nesta área de conhecimento, qual seja: Humanidades. O Geógrafo, além de estudar a geografia humana, deve conhecer o meio físico, consciente de que as relações se afetam, e que a geografia humana não está desassociada da geografia física e vice-versa, tudo está interligado. Uma vez se levando em consideração que tais relações se entrelaçam, e que a aquisição de conhecimentos é diversificada e abrangente ratifica-se aqui a necessidade imprescindível de constantes pesquisas/investigações nessa área de conhecimento visto ser fundamental acompanhar a velocidade de informações que vem ocorrendo na sociedade do conhecimento. A sociedade hoje busca conhecer através do acesso aos meios de comunicação e através das TIC's e um novo mundo se descortina neste caso, estudado em seu espectro social, ou seja, dentre de um conjunto de possibilidades nas mais variadas formas de interação, seja com indivíduos próximos enquanto localidade e ou em outros espaços, com outros indivíduos, dentro de uma perspectiva de novos conhecimentos.

Com uma perspectiva de construção do saber, permite-se que o homem através do seu meio físico, interaja virtualmente determinando novas paisagens e ressignificando o espaço. Assim, admite-se um arranjo espacial para sedimentar o conhecimento e as relações sociais que são tão importantes para o geógrafo-professor-pesquisador e que compreendam o contexto social de que faz parte. E, ao ensinar o aluno interage e possibilita um ensino-aprendizagem conectado com as novas tecnologias. Monbeig (1956 apud Banhara, 2010) quando fala da tarefa do geógrafo-professor-pesquisador de empregar novas tecnologias e novas didáticas e cada vez mais informatizadas que possibilitem que conteúdo da matéria com novas mídias em um mundo repleto de novos saberes e em transformação constante afirma:

“para um mundo moderno convém um ensino moderno e a geografia é uma interrogação permanente no mundo. A evolução do ensino da geografia, nesse sentido, é facilitada pelos contactos de todo o gênero que tem a mocidade com os problemas do dia. A conversação com em família e alguns meios, o rádio, a televisão, os jornais, as atualidades cinematográficas mergulham os jovens, nesse banho de inquietação, pelo menos no que se refere aos debates econômicos. Não é fácil ao professor aproveitar-se disso para animar o seu ensino. Os alunos encontrarão aí uma prova de que a vida não para na porta da classe, a qual deixará de ser um meio artificial”. (p. 20) 
Embora isto aconteça desta forma, é igualmente verdade que a Geografia Humana sofreu transformações no seu padrão à medida que a sua ciência enquanto amplitude evolui, qual seja essa ciência maior: a Geografia. Enquanto objeto de estudo, esta disciplina da Geografia é mantida com uma visão global. Ou seja, como uma ciência dupla, baseada nas ciências naturais para a análise do ambiente, a fim de dar respostas às ciências sociais. A geografia humana, desta forma, concentra-se no estudo de forma integrada; um exemplo disso são as ligações com a Biologia ou a História, sob a teoria sistémica. E, as TICs são ferramentas importantíssimas para o ensino aprendizagem da Geografia Humana e as suas interfaces neste planeta cada vez mais globalizado:

Em suma, a profissão docente deve abandonar a concepção predominante no século XIX de mera transmissão do conhecimento acadêmico, de onde fato provém, e que se tornou inteiramente obsoleta para a educação dos futuros cidadãos em uma sociedade democrática, plural, participativa, solidária, integradora [...] (Imbernón, 2002, p.7).

\section{Metodologia}

O presente a artigo é metodologicamente um estudo qualitativo de revisão da literatura narrativa. Os artigos de revisão narrativa são publicações amplas, correspondentes para delinear e tratar o desenvolvimento ou o "estado da arte" de um apontado assunto, sob ponto de vista teórico ou contextual. Bernardo, et al, (2004). A revisão foi feita a partir de livros e monografias). As revisões de literatura caracterizam-se pela análise e síntese das informações fornecidas por todos os estudos relevantes publicados sobre determinado tema, para sintetizar o corpo de conhecimento existente e concluir a conclusão sobre o tema de interesse. Mancini, Marisa Cotta, e Sampaio, Rosana Ferreira. (2006). Considera-se que todo processo de pesquisa científica começa com um problema, dúvida ou dúvida, o que motiva o pesquisador a buscar informações sobre determinado tema em bibliotecas e / ou bases de dados bibliográficos digitais. (Tasca et al., 1999). Dessa forma, os autores da pesquisa entendem que tal escolha metodológica constitui a contribuição científica mais adequada, no momento, para o tema investigado. A escolha dessa temática se deu através da observação da problemática que constitui a carência de recursos tecnológicos tanto nas Instituições públicas quanto nas privadas e as dificuldades encontradas pelos professores em utilizar equipamentos tecnológicos, devido à escassez dos mesmos, à quantidade mínima de aulas, à dificuldade em manusear os equipamentos e mesmo à falta de tempo para preparar as aulas. Definido nos Parâmetros Curriculares Nacionais (PCNs), o uso de recursos tecnológicos e diferentes fontes de informação contribuem no processo de ensino-aprendizagem e na construção de conhecimento. PCN's (1998):

Com esse tema os professores poderão explorar no imaginário do aluno o significado de alguns recursos técnicos sempre que estes estiverem disponíveis nas escolas, como o computador, as redes de informações, como a internet, e a mídia de um modo geral. A Internet e a mídia vêm redefinindo o comportamento dos lugares e das pessoas entre si. É importante que se trabalhe criticamente com o aluno esse significado para transformações dos lugares e da própria cultura nacional. (Brasil, 1998, pág. 102).

\section{Tecnologias da Informação e Comunicação (Tics) no ensino da Geografia Humana: Percebendo as suas Possibilidades e Limites}

O objetivo do ensino da geografia, entre outros é o de estudar a descrição da terra. Mais tarde esta concepção foi mudando para uma visão onde os fenómenos geográficos são tomados em conceito, o seu contexto é analisado, as suas causas e consequências são apontadas, estabelecendo-se relações entre o fenómeno e o ser humano, sendo definido como a ciência que estuda as relações entre o ser humano e o seu ambiente. O professor de geografia deve estudar o ambiente, estando consciente de que tudo é afetado pela ação humana. Lacoste (2010, p. 91) aborda a importância dessa demanda quando diz que: 
sem dúvida, no caso da geografia, a relação pedagógica veio a ser transformada, pois o mestre não tem mais, como outrora e como ainda acontece com outras disciplinas, o monopólio da informação. (...) Hoje, mestre e alunos recebem ao mesmo tempo, simultaneamente com as atualidades, uma massa de informações geográficas, caóticas. Geografia em pedaços, o ocasional, o espetacular, sem dúvida, mas geografia de qualquer forma.

Entretanto, nos últimos anos, a geografia humana tem vindo a desenvolver-se separadamente da geografia física e vice-versa. Vale a pena insistir na necessidade de reforçar a colaboração entre a geografia física e humana. Precisamos alargar as nossas relações às ciências sociais. E precisamos fazer de forma aberta, decisiva e sem complexos. Em qualquer caso, os problemas requerem soluções integrativas. Cada vez mais, precisamos estabelecer diálogos interdisciplinares, nos posicionarmos em posições multidiciplinares, o que significa estar atentos aos desenvolvimentos em outras disciplinas. Tudo isto de acordo com as necessidades dos problemas em estudo. O professor de geografia deve estudar o ambiente físico, estando consciente de que tudo é afetado pela ação humana. Eventualmente, isto também significa combinar antropologia e economia, geografia e economia, sociologia ou ciência política, geografia com ecologia ou ciências ambientais. Tudo isto de acordo com as necessidades dos problemas em estudo.

Inspirado em Paulo Freire, que ensina que as mudanças demandadas pela educação requerem firmeza de princípios ideológicos e ousadia na prática. Ensinamos a articular teoria e prática, na busca de objetivos bem definidos, que levam para uma ação concreta, transformando homens e sociedades. Nessa busca por novas formas de ensinar, de modo a envolver o aluno do curso de Geografia nesse processo de ensino-aprendizagem, favorecendo sua participação em sala, é possível pensar que a utilização de recursos áudios-visuais se torna um instrumental que contribui para a aprendizagem. Por ser um recurso didático que pode ser utilizado por todas as áreas do currículo escolar, favorecendo uma abordagem geográfica. É uma metodologia que invoca diversos aspectos do processo de aprendizagem: ludicidade, alegria e prazer. O projeto de intervenção pedagógica fundamenta-se na teoria de Lev Semyonovich Vygotsky, que afirma que a linguagem materializa e constitui as significações construídas no processo social e histórico. Quando os indivíduos a interiorizam, passam a ter acesso a estas significações que, por sua vez, servirão de base para que possam significar suas experiências, e serão estas significações resultantes que constituirão sua consciência, mediando, desse modo, suas formas de sentir, pensar e agir. Todas as áreas do currículo escolar, favorecendo uma abordagem geográfica. O professor de Geografia então, deve se apropriar das novas tecnologias a fim de tornar suas aulas instigantes, criando novas condições de aprendizagem. De acordo com Libâneo (2001):

"é necessário valorizar a escola na sua função mediadora entre o aluno e o mundo da cultura, integrando racionalmente, o material/formal do ensino aos movimentos estruturados que visam a transformação da sociedade, com base na pedagogia crítico-social dos conteúdos culturais".

Para Cavalcante (2002, pg.72) percebendo que o desenvolvimento desta cultura é condição para a estruturação de uma sociedade racional e voltada para o crescimento do ser humano, vemos como importante, a estruturação de uma pesquisa, que utilizando bases teóricas sólidas, possa contribuir para o enriquecimento do ensino de Geografia e a subsequente formação de seres pensantes e contextualizados.

\section{A LDB, a Formação e a Utilização das TICs no Ensino}

Segundo a Lei de Diretrizes e Bases da Educação Nacional (LDB), n. 9394/96, em seu Art. 67, Título VI, "a formação de profissionais da educação... terá como fundamentos: I) a associação entre teorias e práticas, inclusive mediante a capacitação em serviço" (Brasil, 1996). A formação didática desde a formação básica, não deixou impune a prática dos professores na sala de aula. Devido ao fato de não saberem como sugerir e relacionar metodologias de ensino e temáticas nas atividades desenvolvidas em sala de aula, todos sentem a falta do conhecimento didático necessário para um processo de 
ensino-aprendizagem mais significativo. A circunstância em que se dá as novas tecnologias midiáticas, que somado as metodologias no processo ensino aprendizagem, podemos perceber todo um desempenho do alunado em suas tarefas cotidianas e na sua formação global com mais participação. Com isto permitindo que as novas mídias em conjunto com os textos que pudesse dizer anteriormente as novas mídias aborrecentes e chatos, passam a ser mais dinamizados em sua nova forma no mundo digital. Importantíssimo dizer que a formação passa a ser mais dinâmica e os professores passam a ter uma nova dimensão didática metodológica com uma nova epistemologia do conhecimento, onde o Professor de Geografia passa a ter um novo modo de união entre a prática e teoria formando nova práxis fazendo com que o ensino da Geografia Humana melhore integrando sua utilização pedagógica com novos saberes. Segundo Lévy (1996), a era atual das tecnologias da informação e comunicação estabelece uma nova forma de pensar sobre o mundo que vem substituindo princípios, valores, processos, produtos e instrumentos que mediam a ação do homem com o meio. Dentre os recursos computacionais que podem auxiliar o processo de ensino e aprendizagem, destacam-se os aplicativos de programas para produção de textos, planilhas, gráfico, Movie Maker e apresentações de trabalhos similares, tais como Word, Excel, PowerPoint e etc. Também sobressaem os jogos educativos e a internet com uma gama imensa de possibilidades através das pesquisas, correio eletrônico, chats, teleconferências e hipertextos e as demais plataformas que vieram somar nesse momento de pandemia e trabalho remoto, tais como o ZOON, Meet e tantos outros. A partir dessa constantação, Perrenoud afirma para o educador que:

O mundo do ensino, ao invés de estar sempre atrasado em relação a uma revolução tecnológica, poderia tomar a frente de uma demanda social orientada para a formação. Equipar e diversificar as escolas é bom, mas isso não dispensa uma política mais ambiciosa quanto às finalidades e às didáticas. (Perrenoud, 2000, p. 138)

Uma ação educadora inovadora precisa considerar a instrumentalização desses recursos disponíveis. O aprendizado ocorre pelo fato de o aluno estar executando uma tarefa por interferência do computador. Esta tarefa pode ser a preparação de um texto através de um processador, uma análise num banco de dados já existente, a resolução de problemas de diversos domínios do conhecimento e a reprodução desta resolução de acordo com uma linguagem de programação, o controle de procedimentos em tempo real como objetos que se movem no ambiente. Assim, propõe a utilização do computador, em seus mais diversos aplicativos, nas práticas metodológicas do ensino de Geografia em sala de aula. Segundo Lévy (1996), a era atual das tecnologias da informação e comunicação estabelece uma nova forma de pensar sobre o mundo que vem substituindo princípios, valores, processos, produtos e instrumentos que mediam a ação do homem com o meio. A tecnologia tem efeitos positivos nas atitudes dos alunos em relação à aprendizagem e no seu auto-conceito. A sua utilização leva-os a sentir maior sucesso na escola, maior motivação para aprenderem.

Hoje o computador está acessível a um grande número de pessoas e a universidade deve propiciar a utilização e aproveitamento desse recurso para melhorar o desempenho dos alunos nos cursos de geografia. Não podemos falar da utilização da tecnologia da informática na educação sem abordarmos a questão da aprendizagem. A informática tem um papel concernente neste processo tendo em vista ser somente uma ferramenta que irá auxiliar na aprendizagem do aluno. Esse saber, independente das tecnologias, servirá como um instrumento a mais para o professor criar novos espaços de atuação e interação, para aluno utilizar esses recursos na sala de aula. A partir desta verificação, professor e aluno poderão criar situações de aprendizagens expressivas intercedidas pelas novas tecnologias. A tecnologia tem efeitos positivos nas atitudes dos alunos em relação à aprendizagem e no seu autoconceito.

\section{Novas Representações e Novos Signos no Ensino Aprendizagem com as TICs}

Com a possibilidade de utilizarmos a informática através de sua popularização e com isto a sociedade passa a ter novos mecanismos de acesso possibilitando uma nova abordagem a partir da informação que passa a gerar novas palavras no 
cotidiano estudantil, acadêmico, ou seja, no ambiente educacional tais como internet, software, mouse, download, link, e-mail, backup dentre outras, interferindo de forma cada vez mais evidente nesse ambiente. Assim, pensar no ensino de Geografia, com as novas mídias a contribuição é real e o aperfeiçoamento do trabalho docente, no uso das novas técnicas em sala de aula, ajudam significativamente nossos alunos na assimilação e na produção de conhecimento e de informações. O surgimento de novas tecnologias proporcionou uma série de modificações na sociedade, interferindo de forma significativa no mundo capitalista, inclusive no campo da educação (Tellaroli e Albino, 2007).

O grande avanço tecnológico que marcou os períodos pós-guerras e os anos finais do século XX foi responsável pelo desenvolvimento de diversos dispositivos eletrônicos que rapidamente foram inseridos no mercado capitalista tornando-se de vital importância econômica e social para os países onde foram desenvolvidos e, posteriormente, para os países em desenvolvimento que passaram a utilizá-los e, consequentemente, para as suas populações.

Por muito tempo reservados aos militares para cálculos científicos, seu uso civil disseminou-se durante os anos 60. Já nessa época era previsível que o desempenho do hardware aumentaria constantemente. Mas que haveria um movimento geral de virtualização da informação e da comunicação, afetando profundamente os dados elementares da vida social, ninguém, com a exceção de alguns visionários, poderia prever naquele momento. (Levy, p. 29).

Hoje, caracterizado pelas constantes transformações o nosso Planeta Terra, passa por inovações tecnológicas que se tornaram responsáveis por nos conectar com o mundo digital por equipamentos móveis, influenciando cada vez mais o nosso cotidiano, tanto em aspectos pessoais como também nos profissionais (Castells, 1990, p. 4). As mídias tecnológicas aproximaram as pessoas geograficamente distantes e fez com que notícia instantaneamente fosse vinculada em sites de notícias de qualquer parte do planeta, espalhando essa notícia em questões de minutos para toda a Terra. Desta forma, as transformações geradas pelos meios de comunicação sofrem transformações muito rapidamente:

É impossível separar o humano de seu ambiente material, assim como dos signos e das imagens por meio dos quais ele atribui sentido à vida e ao mundo. Da mesma forma, não podemos separar o mundo material — e menos ainda sua parte artificial - das ideias por meio das quais os objetos técnicos são concebidos e utilizados, nem dos humanos que os inventam, produzem e utilizam. (Levy, p. 19)

Existe a disponibilidade dos professores em utilizar da tecnologia, entretanto existe um obstáculo que é a falta de recursos financeiros e de investimentos por parte dos governos e empresários que acabam deixando o ensino de forma precária e limitando a aquisição e a disposição de equipamentos para todas as salas de aulas, além da consequente precarização da capacitação docente. Os recursos tecnológicos têm sido introduzidos no sistema educacional e que os professores estão em constante atualização, intensificando a transmissão de conhecimento para os estudantes modificando de forma significativa o papel do professor em sala de aula. $\mathrm{O}$ avanço tecnológico tem, de forma significativa, interferido em praticamente todos os setores da sociedade, modificando intensamente o cotidiano dos indivíduos, inclusive no ambiente educacional. Os recursos tecnológicos como computadores e celulares estão cada vez mais incorporados ao processo educacional, criando uma nova realidade que torna necessária a capacitação constante dos professores e, consequentemente, dos alunos. Por outro lado, a realidade educacional brasileira demonstra que ainda não existe uma infraestrutura adequada em todas as escolas, surgindo, assim, a necessidade da introdução dessas tecnologias no ambiente educacional e utilização delas como recurso didático nas aulas. Para os alunos é natural as tecnologias digitais. A geração de hoje, estabeleceu configurações de convivência com outros sujeitos, de uma forma própria e particular, ligados aos espaços digitais virtuais, construindo o que Castells (1999) denomina "Cultura da virtualidade real". A contemporaneidade gera um novo movimento nas maneiras de ensinar e aprender. Hoje o professor já não é visto como o único detentor do conhecimento. A internet e as redes sociais possibilitam a participação e a 
atuação do público alvo, ou seja os alunos no momento em que favorecem facilmente subsídios satisfatórios para debates e reflexões sobre os atributos e as características físicas, econômicas, sociais, culturais e políticas do lugar onde ele mesmo vive:

A internet como instrumento potencializador traz inúmeras possibilidades através das ferramentas do Google Earth e Google Maps, pelas quais esses alunos podem explorar o espaço interno e os pontos circunvizinhos da escola, casa, bairro, cidade, estado e país através de registros fotográficos. Dessa forma, explorar os instrumentos que a escola disponibiliza em sala de aula (mapas, representações, simulações, explorações de situações cotidianas) podem gerar provocações para que, quando estes alunos, estiverem logados em espaços virtuais possam comparar os registros às imagens digitais disponibilizadas na rede (Nascimento; Hetkowisk, 2011, pp. 3522-3523).

Diante da globalização que vivenciamos com o avanço da ciência, da tecnologia e da informação como as ferramentas hoje a nosso dispor podem ajudar no processo de ensino aprendizagem. Entretanto, o investimento financeiro se faz necessário para a efetivação de implementação das TICs, sobretudo nas Instituições Públicas onde os Recursos Financeiros sempre são escassos. E, fazemos coro com Saviani (2009) quando afirma que a questão do uso das Tecnologias digitais na educação não pode ser dissociada do problema das condições de trabalho, notadamente as questões do salário e da jornada de trabalho. Com efeito, as condições precárias de trabalho não apenas neutralizam a ação dos professores, mesmo que sejam bem formados como dificultam uma boa formação, pois operam como fator de desestímulo à procura pelos cursos de formação docente e à dedicação aos estudos e à pesquisa.

Lima (2010:164) comenta: "O professor como sujeito que não reproduz apenas o conhecimento pode fazer do seu próprio trabalho de sala de aula um espaço de práxis docente e de transformação humana". No ensino de Geografia conforme Neves e Muniz (2018) os procedimentos de ensino-aprendizagem também têm passado por profundas modificações para receber os avanços advindos das novas tecnologias, com a utilização de ferramentas inovadoras tais como aplicativos que usam mapas tridimensionais. Esses recursos são utilizados, sobretudo como mediadores de aprendizagem utilizando-se de imagens de satélites aplicadas no ensino da Geografia Humana quando da Leitura e interpretação de quadros, mapas e diagramas, porém, se faz necessário pensar em instrumentos que possam auxiliar no ensino. Por exemplo, utilizando computador, internet, google maps é crível analisar a influência da globalização no espaço geográfico em escala local. O professor pode também aliar as TICs ao cotidiano escolar ao realizar atividade junto aos alunos ao acesso a produtos cartográficos digitais e interpretar paisagens, com o uso do computador, internet, sites e demais conteúdos educacionais. Com o google Earth uma ferramenta que apresenta uma projeção tridimensional do globo terrestre, tendo diversas imagens do globo a partir de satélites é possível particularizar e disponibilizar para o aluno através da pesquisa relacionada ao espaço delimitado identificar problemas econômicos, geopolíticos e ambientais em escala tanto local, quanto global. Os blogs e demais ferramentas do mundo virtual são maneiras construtivas para desenvolvimento de conteúdo, sendo espaços virtuais para publicação de uma produção significatica. O cinema disponibilizado para baixar via internet pode tornar-se uma ferramenta importante para trabalhar conceitos geográficos, seja em filmes, animações ou documentários já existentes ou mesmo na criação de novos projetos cinematográficos com os alunos.

\section{O Professor de Geografia e as Novas Possibilidades Apresentadas com as TICs}

Diversas teorias com sua metodologia própria dentro das matérias na academia têm abordado a importância de ferramentas como: Word e ou similares para digitação de textos, trabalhos, monografias, bem como das ferramentas do Excel e suas similares, para a organização, na preparação de slides, que nas próximas décadas e ou anos se tornaram novas ferramentas que auxiliaram metodologicamente a didática na formação de novos professores da Geografia Humana. Nas Instituições Educacionais sejam elas Faculdades e ou nas escolas em que o ensino aprendizagem se dá de forma democrática a atuação do profissional em interação com as novas mídias tecnológicas proporciona que o educador possa de fato ser um 
protagonista e aprimora sua práxis com liberdade pedagógica e que permite interações frutíferas junto aos demais personagens da escola, possibilitando a construção de um sabor democrático, segundo Moran:

Portanto, na prática pedagógica o professor deve propor metodologias que contemplem elaboração de projetos que provoquem um estudo sistemático, uma investigação orientada, para ultrapassar a visão de que o aluno é um objeto, e torná-lo sujeito e produtor do seu próprio conhecimento (Moran, 2000, p.86).

Constata-se nas mais diferentes metodologias de trabalho nas salas de aulas com uma formação voltada com a aderência da utilização das novas mídias com a integração de vídeos, sons, documentários, e todos os aplicativos disponibilizados pela internet com custos acessíveis permitindo novas interações. Cavalcanti (2004) acentua a necessidade de a escola instigar a colaboração voluntária do aluno no processo de construção do conhecimento mediante a criatividade do educador e a inserção de recursos e ações que tornem as aulas de Geografia uma construção constante:

Para superar o formalismo didático no ensino de Geografia é preciso, entre outras coisas, que seus agentes professores e alunos - estejam realmente envolvidos no processo de ensino requer do professor a organização de atividades levando em conta as necessidades individuais e sociais dos alunos, as condições concretas em que o ensino se realiza e os modos mais adequados de tratamento dos conteúdos para que os alunos estejam em atividade intelectual permanente e possam, assim, construir seu conhecimento. (Cavalcanti, 2004, p. 133)

As propostas que contemplem o diálogo aberto do ambiente escolar com as tecnologias de comunicação levam a reflexões pertinentes e favoráveis a uma educação mais midiática no sentido de utilização de novas ferramentas do mundo da informatização (Oliveira, 2004, p. 29). Atualmente a academia defende também a importância do reconhecimento da função mediadora da escola que casa a mediação entre aluno escola e o mundo que o rodeia no desenvolvimento da cultura como necessária à formação de indivíduos capazes de elaborar críticas, reflexões, análises e opiniões pessoais próprias e não simplesmente, reprodutores de estereótipos fornecidos pela grande mídia (Libâneo, 2001; Cavalcante, 2002). Os recursos eletrônicos ajudam as pessoas a obter uma visão global do mundo e, não somente local, por intermédio do contato viabilizado através do acesso rápido e simples quer dentro de um curto intervalo de tempo, quer em espaços longos e duradouros, novos signos e significados (lugares, idiomas, culturas, costumes, religiões, doutrinas e ideias) estão presentes:

Nessa conjuntura, em que o processo de evolução das novas mídias, representa um importante aliado para uma expressão mais didática de temas e assuntos, é possível perceber que o desempenho do aluno nas atividades de sala de aula é mais participativo e propositivo. As novas mídias permitem inclusive que os textos ou atividades que outrora se tornavam maçantes, sejam mais dinâmicos na nova forma: digital. É importante, no entanto, ressaltar que a formação e um conhecimento bastante amplo são condições necessárias para a prática do professor. Ele deve saber Geografia para poder melhor explorar essa metodologia, que é interdisciplinar, pois, podem-se desenvolver atividades integrando todas as áreas do currículo escolar (Banhara, 2010, p. 6).

Os meios de comunicação, especialmente a televisão e hoje as plataformas de vídeo instalados nos aparelhos de celulares e tabletes são essenciais ao desenvolvimento e permite que o aluno tenha uma independência desde que sejam usados corretamente. Em referência a esse assunto Faria (2004) sugere que:

A TV e o vídeo também devem ser bem analisados e planejados para se constituírem num recurso de enriquecimento e interatividade. A técnica do cine-fórum, por exemplo, é uma forma de levar os alunos a refletir e dialogar sobre o tema do filme, relacionando-o ao conteúdo da disciplina. Novamente, como na escolha dos softwares, temos que ter critérios para a escolha do filme e um roteiro básico da aula com o uso do vídeo. 
As utilizações de tais equipamentos como ferramentas na cultura tecnológica, vão possibilitar que cada dia mais a utilização dessas ferramentas transformem-se em potencialidades metodológicas e didáticas nos processos do ensino com nova mediação multimeios e tecnológicos. Moran (2000) deixa claro que:

Não basta apenas levar os modernos equipamentos para a escola, como querem algumas propostas oficiais. Não é suficiente adquirir televisões, videocassetes, computadores, sem que haja uma mudança básica na postura do educador, pois isso reduzirá as tecnologias a simples meios de informação (p. 38).

\section{Considerações Finais}

Não é as TICs que vão ser a salvação ou redenção das mazelas educacionais que o Brasil enfrenta e por conseguinte o ensino aprendizagem da Geografia Humana. Todavia, poderá colaborar se for utilizada de forma a minimizar a falta de recursos e promover novas práxis no mundo educacional de nossos futuros profissionais da Geografia. Com a incorporação das TICs nas salas de aulas, o educador primeiramente deverá ter o domínio do conteúdo e buscar ter uma prática pedagógica includente, verdadeiramente democrática que tenha como norte a edificação permanente de novos conhecimentos, todavia frisamos que também é possível que a má utilização das tecnologias vem a permitir alguns desentendimentos, pois, nem tudo é permitido enquanto tecnologias a serem empregadas sem o devido cuidado metodológico e didático. As escolas brasileiras, estão infelizmente sem as ferramentas necessárias que acompanhem as novas tecnologias e faz com que tanto os professores quanto os alunos tenham que pressionar em conjunto com a comunidade para que as mudanças necessárias sejam de fato implementadas. Ou seja, todos os atores das comunidades escolares precisam estar em dia como acesso e saber manusear todas as ferramentas a disposição nesse mundo tecnológico que se apresenta. O desenvolvimento de seu trabalho trelado a sua teoria e pratica, a tão sonhadas práxis em prol do ambiente educacional acompanhado da novas TICs são de fato um divisor de águas. Entretanto, seria um grave erro, o professor de Geografia adotar uma visão retroativa acerca das novas tecnologias. Ao invés de constituírem um empecilho para o processo de ensino-aprendizagem, elas se fazem imprescindíveis quais meios viáveis que permitam aos alunos enxergar os conteúdos debatidos em sala de aula em direções mais além das paredes da escola.

As novas tecnologias, que sempre estão passando por novos estágios de evolução, basicamente não precisam ser encaradas pelo educador como um obstáculo para a execução do processo ensino-aprendizagem. Nesse contexto pós-moderno caracterizado pelo atual avanço técnico-científico-informacional, ele pode se utilizar de modo seletivo das facilidades e opções que delas emanam para ajudá-lo a propiciar condições favoráveis para a mudança de paradigmas que possibilitem se trabalhar com os alunos, elementos de seu interesse e de seu cotidiano, como no caso das apresentações multimídia. O estudo proposto é justificável por permitir evidenciar como as tecnologias digitais auxiliam o trabalho do professor como mediador durante a ministração dos conteúdos, visando contribuir para a apropriação dos conteúdos, o desenvolvimento da autonomia e o pensar crítico do aluno. Para tanto, foi realizada pesquisa bibliográfica com embasamento teórico em autores da Geografia e Ensino; identificação de tecnologias digitais de informação e comunicação voltados para o ensino de Geografia e proposição de utilização das TICs junto aos conteúdos geográficos.

Os debates que rodeiam e integram o desenvolvimento de novas propostas de inserção das novas tecnologias no ensino da Geografia não se encerram, pois, a evolução tecnológica é constante, assim como as novas práticas e/ou aperfeiçoamento do ensino/aprendizagem. Atualmente constata-se que as TICs estão acessíveis para muitas pessoas, sejam no seu dia-a-dia, seja nos ambientes escolares e com isto devem motivar a utilização e aproveitamento desse recurso para melhorar o desempenho dos alunos. A instalação das tecnologias de multimídia nas escolas deve constituir-se em mais um elemento que o professor pode e deve aproveitar, para explorar a capacidade dos seus alunos.

Quanto às contribuições para estudos futuros os autores intentam no artigo ofertar subsídios para aprofundamento de pesquisas posteriores nessa área de conhecimento com a temática descrita visto que se confere de tal modo uma possibilidade 
inovadora no processo de ensino aprendizagem criando ambientes transformadores e estimulantes com uso de TICs, tanto para os docentes quanto para discentes, estimulando-os na construção coletiva e potencializando melhorias da qualidade do ensino e na assimilação constante de conhecimentos compatíveis com as demandas impostas pela sociedade da informação. Acrescida a tal situação ressalta-se a atual carência de pesquisas e consequente necessidade de constantes e intensas discussões no ensino de Geografia. Nesse sentido, a utilização das TICs aliada a práxis de pesquisas no contexto do ensino da Geografia podem fomentar novas percepções estimulando inovadoras pesquisas que favoreçam a evolução sociocontemporânea seja dos Geógrafos seja dos docentes pesquisadores da Geografia e de seus discentes que serão futuros geógrafos/pesquisadores em todos as domínios sedimentando e inovando a busca constante de novos caminhos para fortalecimento e expansão dessa área de conhecimento.

\section{Referências}

Banhara G. D. (2010). A Utilização das Novas Tecnologias no Ensino de Geografia. http://www.dge.uem.br/iii-encontro-regional-de-geografia-e-xxv-semanade-geografia-uem.

Bernardo W.M., Nobre M.R.C. \& Jatene F.B. (2004). A prática clínica baseada em evidências. Parte II: buscando as evidências em fontes de informação. Rev Assoc Med Bras. 50(1),1-9.

Brasil. (1998). Parâmetros Curriculares Nacionais para o Ensino Fundamental. Ministério da Educação.

Castells, M. (1999). A sociedade em rede. (3a ed.), Paz e Terra

Cavalcanti, C. (2021). Uma tentativa de caracterização da economia ecológica. Ambient. soc., 7.http://dx.doi.org/10.1590/S1414- 753X2004000100009.

Cavalcanti, L. de S. (2002). Geografia e práticas de ensino. Goiânia: Alternativa

Faria, E. T. (2004). O professor e as novas tecnologias. In: Enricone, D (Org.). Ser professor. (4a ed.), EDIPUCRS, pp. $57-72$.

Imbernón, F. (2002). Formação Docente e Profissional: Formar-se para a mudança e a incerteza. (3a ed.), Cortez. (Coleção Questões da Nossa Época: v. 77).

Lacoste, Y. (2010). A Geografia: isso serve, em primeiro lugar, para fazer a guerra. (18a ed.), Papirus

Levy, P. (2009). Cibercultura. (Trad. Carlos Irineu da Costa). Editora 34, 2009.

Levy, P. (2013). Conceitos-chave no estudo da cibercultura. https://www.cafecomsociologia.com/pierre-levy-conceitos-chave-cibercultura/>

Libâneo, José Carlos. (2001). Adeus professor, adeus professora? Novas exigências educacionais e profissão docente. (5a ed.), Cortez, (Coleção questões da Nossa Época, V. 67).

Lima, M. L., Gomes, M. (2010). Redimensionando o papel dos profissionais da educação: algumas considerações. In: Pimenta, Selma Garrido, Ghedin, Evandro(orgs). Professor reflexivo no Brasil: gênese e crítica de um conceito. (6a ed.), Cortez

Mancini, M. C. \& Sampaio, R. F. (2006). Quando o objeto de estudo é a literatura: estudos de revisão. Brazilian Journal of Physical Therapy, 10(4). https://dx.doi.org/10.1590/S1413-35552006000400001

Moran, J. (2000). Ensino e aprendizagem inovadores com tecnologias audiovisuais e telemáticas, In: Moran, J., Masetto, M. \& Behrens, M. Novas tecnologias e mediação pedagógica. Papirus.

Neves, B. P., Muniz, \& Alexsandra M. V. (2004). As Tecnologias Da Informação E Comunicação (Tic S ) E A Geografia: Aplicações No Ensino Da Geografia Humana. In: V CONEDU, 2018, REcife. Anais do V Conedu. REalize, 2018.

Oliveira, M. R. R. de. (2004). O Primeiro Olhar: Experiência com Imagens na educação Física Escolar. 2004.177 f. Tese (Mestrado em Educação Física) Centro de Desportos - Universidade Federal de Santa Catarina/UFSC.

Perrenoud, P. (2000). Utilizar novas tecnologias. In: Dez novas competências para ensinar. Artmed

Saviani, D. (2009). Formação de professores: aspectos históricos e teóricos do problema no contexto brasileiro. Revista Brasileira de Educação 14

Tasca, J. et al. (2010). An approach for selecting a theoretical framework for the evaluation of training programs. Journal of European Industrial Training, 34, $631-655.2010$

Tellaroli, T. M., \& Albino, J. P. (2007). Da sociedade da informação às novas tic's: questões sobre internet, jornalismo e comunicação de massa. https://www3.faac.unesp.br/anais-comunicacao/textos/28.pdf .

Vygotsky, L. S. (1996). A formação social da mente: o desenvolvimento dos processos psicológicos superiores. (5a ed.), Martins Fontes. 